\title{
Criptógamos do Parque Estadual das Fontes do Ipiranga, São Paulo, SP, Brasil. Algae 45: Bacillariophyceáe (Naviculales: Brachysira)
}

\author{
io Angela Maria da Silva-Lehmkuhl ${ }^{1,3}$, io Elton Augusto Lehmkuhl ${ }^{1}$, ${ }^{\text {io }}$ Simone Alves de Oliveira ${ }^{2}$, \\ io Krysna Stephanny de Morais ${ }^{2}$, ${ }^{\text {Denise C. Bicudo }}{ }^{2}$ e ${ }^{\text {Carlos Eduardo de Mattos Bicudo }}{ }^{2}$
}

Recebido: 8 maio 2019; aceito: 20 janeiro 2020

Como citar: Silva-Lehmkuhl, A.M., Lehmkuhl, E.A., Oliveira, S.A., Morais, K.S., Bicudo, D.C. e Bicudo, C.E.M. 2020. Criptógamos do Parque Estadual das Fontes do Ipiranga, São Paulo, SP, Brasil. Algae 45: Bacillariophyceae (Naviculales: Brachysira). Hoehnea 47: e502019. http://dx.doi.org/10.1590/2236-8906-50/2019.

ABSTRACT - (Cryptogams of the Parque Estadual das Fontes do Ipiranga, São Paulo, São Paulo State, Brazil. Algae, 45: Bacillariophyceae (Naviculales: Brachysira)). The floristic survey of Brachysira Kützing (Naviculales) of the Parque Estadual das Fontes do Ipiranga (PEFI), São Paulo, São Paulo State, Brazil, resulted from the analysis of 31 permanent preparations of diatom material collected between years 1991 and 2017. The water and substrate samples (macrophytes and rocks) from lentie systems, streams and the hydrophytoterium were collected and subsequently were oxidized for analysis under light microscope. Nine species and one morphotype were identified from 15 diatom slides, of which four species are new records for Brazil (Brachysira cf. caleicola Lange-Bertalot, Brachysira frenguellii (Manguin) Lange-Bertalot \& Moser, Brachysira huitotarum Vouilloud, Sala \& Núñez-Avellaneda and Brachysira intermedia (Østrup) Lange-Bertalot). Brachysira subrostrata Lange-Bertalot was registered for the first time in the State of São Paulo.

Keywords: brebissonii-complex, diatoms, floristic survey, microalgae

RESUMO - (Criptógamos do Parque Estadual das Fontes do Ipiranga, São Paulo, SP, Brasil. Algae, 45: Bacillariophyceae (Naviculales: Brachysira)). O levantamento florístico do gênero Brachysira Kützing (Naviculales) do Parque Estadual das Fontes do Ipiranga (PEFI), São Paulo, SP, Brasil, resultou da análise de 31 preparações permanentes de material coletado entre 1991 e 2017. As amostras de água e de substratos (macrófitas e rochas) de sistemas lênticos, riachos e do hidrofitotério foram coletadas e posteriormente oxidadas para análise ao microscópio de luz. Nove espécies e um morfotipo foram encontrados em 15 amostras de material do PEFI, sendo quatro novas citações para o Brasil (Brachysira cf. calcicola Lange-Bertalot, Brachysira frenguellii (Manguin) Lange-Bertalot \& Moser, Brachysira huitotarum Vouilloud, Sala \& Núñez-Avellaneda e Brachysira intermedia (Østrup) Lange-Bertalot). Brachysira subrostrata Lange-Bertalot foi registrada pela primeira vez no Estado de São Paulo.

Palavras-chave: complexo-brebissonii, diatomáceas, levantamento florístico, microalgas

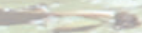

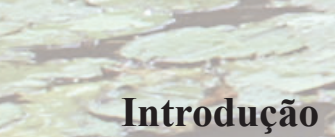

O gênero Brachysira foi proposto por Kützing (1836) tendo como espécie-tipo Brachysira aponina Kützing. Onze anos mais tarde, essa espécie foi transferida pelo próprio Kützing (1844) para o gênero Navicula Bory e mais de um século depois, não havia sido mais registrada na literatura.

Round \& Mann (1981) analisaram amostras de um testemunho vulcânico da região de Santorini, na Itália, e encontraram uma forma naviculoide pouco conhecida na época, mas que já havia sido citada por Berg (1952) como Caloneis perlepida (Grunow)Berg e por Karayeva \& Shevchenko (1974) como Caloneis savitschii Karayeva e Navicula dvorachekii Ehrlich (1978). Após análise dos espécimes de Santorini ao microscópio de luz, Round \& Mann (1981) sugeriram que estes não deveriam ser colocados em qualquer dos gêneros antes citados por serem mais próximos de Anomoeoneis Pfitzer. No entanto, ao analisarem Anomoeoneis sphaerophora (Kützing)

1. Universidade Federal do Amazonas, Instituto de Ciências Sociais, Educação e Zootecnia, Estrada Parintins-Macurany, $1.805,69152-$ 240 Parintins, AM, Brasil

2. Instituto de Botânica, Núcleo de Pesquisa em Ecologia, Av. Miguel Estéfano, 3.687, 04301-902 São Paulo, SP, Brasil

3. Autor para correspondência: angela_ecologia@yahoo.com.br 
Pftizer, a espécie-tipo do gênero, Round \& Mann (1981) verificaram que a forma naviculoide também não autorizava a classificação de tal material em Anomoeoneis. Posteriormente, a análise da coleção de Kützing revelou aos referidos autores que se tratava, na verdade, de Brachysira aponina, que concordava com a forma naviculoide que estavam à procura e restabeleceram o gênero Brachysira com emendas à descrição original e transferência de outras espécies para o gênero.

O gênero Brachysira é comum em águas doce e marinha, possui táxons considerados endêmicos (Metzeltin \& Lange-Bertalot 1998, 2007) e, em geral, apresenta espécies com estreito espectro de tolerância ambiental, com preferência por ambientes oligotróficos indicando, com isso, a boa qualidade ecológica das águas que habitam (Cantonati et al. 2017). Morfologicamente, seus representantes são caracterizados por serem unicelulares, com valvas lineares lanceoladas ou rômbicas, de ápices rostrados, capitados ou arredondados. A face valvar é plana, ornamentada com espinhos, verrugas ou costelas longitudinais e o contorno valvar é quase todo margeado por um espessamento proeminente. As estrias são unisseriadas, com aréolas alongadas transapicalmente. O esterno da rafe é estreito, podendo expandir-se na região central e é contornado por costelas longitudinais. As terminações da rafe são simples. A característica mais marcante dos representantes deste gênero é a presença de linhas hialinas longitudinais, que podem ser delicadas ou mais espessas e que separam as fileiras de aréolas das estrias (Round \& Mann 1981, Round et al. 1990).

Até 1994, Brachysira contava com pouco menos de 15 espécies e a revisão de Lange-Bertalot \& Moser (1994) incluiu 32 novas espécies e outras 35 foram transferidas para o gênero. Após esse trabalho, 39 espécies novas foram descritas para o gênero, 22 das quais para a região tropical da América do Sul (Metzeltin \& Lange-Bertalot 1998, 2007, Vouilloud et al. 2014, Mora et al. 2017). Outros novos táxons e estudos que ampliaram o número de espécies conhecidas advieram de estudos florísticos, principalmente, regionais (Souza \& Compère 1999, Witkowski et al. 2000, Wolfe \& Kling 2001, Werum \& Lange-Bertalot 2004, Shayler \& Siver 2004a, 2004b, Anderson et al. 2013, van de Vijver 2014, Potapova et al. 2014, Kennedy \& Allott 2017). Até o momento, o gênero conta com 121 espécies taxonomicamente aceitas (Guiry \& Guiry 2019).
Não há no Brasil um estudo que tenha sido realizado especificamente sobre Brachysira, e todo o conhecimento atual das espécies deste gênero decorre de estudos florísticos feitos a partir de material de substratos artificiais e naturais e de sedimentos de rios e lagos, com condição desde oligotrófica a eutrófica. Até o momento, 18 espécies são conhecidas para o Brasil (Metzeltin \& Lange-Bertalot 1998, 2007, Tremarin et al. 2009, Silva et al. 2010, Bertolli et al. 2010, Canani et al. 2011, Santos et al. 2011, Silva et al. 2011, Bes et al. 2012, Marra et al. 2016, Faustino et al. 2016, Costa et al. 2017, Bartozek et al. 2018), sendo as regiões norte, nordeste e centro-oeste sub-amostradas para o gênero.

O conhecimento da diatomoflórula do PEFI está reunido nas publicações de Morandi et al. (2006), Carneiro \& Bicudo (2007), Rocha \& Bicudo (2008), Marquardt \& Bicudo (2014), Ferreira \& Bicudo (2017) e Morais et al. (2019). O presente estudo tem por objetivo realizar pioneiramente o levantamento das espécies de Brachysira presentes no PEFI, contribuindo para o conhecimento do gênero no Estado de São Paulo.

\section{Material e métodos}

O Parque Estadual das Fontes do Ipiranga (PEFI) está situado entre os paralelos $23^{\circ} 38^{\prime} 08^{\prime \prime S}$ e $23^{\circ} 40^{\prime} 18^{\prime \prime} \mathrm{S}$ e os meridianos 46잉 $36^{\prime} 48^{\prime \prime} \mathrm{W}$ e $46^{\circ} 38^{\prime} 00^{\prime \prime} \mathrm{W}$ e representa um dos mais importantes remanescentes de Mata Atlântica inseridos em área urbana do país. Localizado na cidade de São Paulo, SP, o PEFI foi criado com o objetivo de preservar ecossistemas naturais de grande relevância ecológica, já que é formado por áreas parcial ou totalmente inalteradas, que possuem grande significado científico (Bicudo et al. 2002). Ainda, o Parque é expressivo em recursos hídricos que abrigam imensa diversidade biológica.

As amostras analisadas foram coletadas entre os anos 1991 e 2017 e foram depositadas no acervo do Herbário Científico do Estado "Maria Eneyda P. Kauffmann Fidalgo" (SP) do Instituto de Botânica da Secretaria de Infraestrutura e Meio Ambiente do Estado de São Paulo. Trinta e uma preparações foram examinadas para conhecer a ocorrência de espécies de Brachysira em amostras de água e substratos naturais de corpos d'água do PEFI. Entre os ambientes, o Parque também possui um hidrofitotério, isto é, um ambiente para exposição de plantas aquáticas, de onde foram coletadas amostras de material aderido a macrófitas. O material planctônico foi obtido com rede de plâncton 
de malha de $20 \mu \mathrm{m}$ e o material perifítico foi obtido a partir de espremido manual de partes submersas de diferentes macrófitas (Ferreira \& Bicudo 2017). Informações disponíveis sobre as amostras (sigla do herbário e número de acesso à coleção, local de coleta, data de coleta e hábitat) estão compilados na tabela 1. Solução aquosa de formalina 3-5\% (Bicudo \& Menezes 2017) foi utilizada para fixar e preservar as amostras.

Para análise das diatomáceas foram preparadas lâminas permanentes a partir de subamostras oxidadas utilizando as técnicas de Simonsen (1974) modificada por Moreira-Filho \& Valente-Moreira (1981), a qual utiliza $\mathrm{K}_{2} \mathrm{MnO}_{4}$ e $\mathrm{HCl}$; e a de Battarbee (2001) que usa $\mathrm{H}_{2} \mathrm{O}_{2}(35 \%)$ aquecido e $\mathrm{HCl}(37 \%)$ a frio. Os meios de inclusão usados foram Naphrax (I.R. = 1,74), Hyrax $(\mathrm{I} . \mathrm{R} .=1,61)$ e Zyrax $(\mathrm{I} . \mathrm{R} .=1,7)$ dependendo da época em que foram providenciadas as preparações.

Os materiais foram analisados ao microscópio óptico binocular Zeiss, modelo Axioskop 2 plus, equipado com contraste de fase e sistema de captura de imagem Axiocam ERc5s, em aumento de 1.000×.

O estudo taxonômico dos espécimes foi baseado, sempre que possível, em análise populacional. Os táxons identificados foram ilustrados, medidos e descritos seguindo o padrão de descrição adotado para o gênero. $\mathrm{O}$ enquadramento taxonômico para as categorias supraordinais foi baseado em Medlin \& Kaczmarska (2004) e em Round et al. (1990) para as categorias subordinais. A identificação dos táxons baseou-se em literatura específica para o gênero (ex. Lange-Bertalot \& Moser 1994) e literatura com proposição de novas espécies (ex. van de Vijver 2014, Kennedy \& Allot 2017). Espécies marcadas com um asterisco $(*)$ constituem novas citações para o Estado de São Paulo e com dois (**) novas citações para o Brasil.

\section{Resultados e Discussão}

O levantamento das espécies do gênero Brachysira do PEFI resultou na identificação de nove espécies e um morfotipo. Características morfométricas estão compiladas na tabela 2 para melhor comparação entre os táxons.

Enquadramento taxonômico:

Classe Bacillariophyceae Haeckel 1878 emend. Medlin \& Kaczmarska 2004

Ordem Naviculales Bessy 1907

Família Brachysiraceae D.G. Mann in Round et al. 1990

Gênero Brachysira Kützing 1836

Brachysira brebissonii Ross. Journal of the Marine Biological Association of the United Kingdom 66(3): 607. 1986.

Figuras 1-11

Tabela 1. Principais informações sobre as amostras de Brachysira do Parque Estadual das Fontes do Ipiranga, São Paulo, SP, Brasil. Table 1. Main information about Brachysira samples of the Parque Estadual das Fontes do Ipiranga, São Paulo, São Paulo State, Brazil.

\begin{tabular}{lccc}
\hline Local de coleta & $\begin{array}{c}\text { Sigla do Herbário e número } \\
\text { de acesso }\end{array}$ & Data da coleta & Hábitat \\
\hline \multirow{2}{*}{ Hidrofitotério } & SP255745 & 18 -VII-1991 & epifítico \\
& SP469783 & $12-$ IV-2017 & planctônico \\
& SP294903 & $07-$ XI-1996 & epifítico \\
& SP255747 & 18 -VII-1991 & epifítico \\
Lago dos Bugios & SP255748 & 18 -VII-1991 & planctônico \\
& SP294901 & $07-$ XI-1996 & epifítico \\
& SP294902 & $07-X I-1996$ & planctônico \\
Lago do Instituto de Astronomia, Geofísica e & SP294906 & $15-$ I-1997 & epifítico \\
Ciências Atmosféricas (Lago do IAG) & SP294907 & $15-$ I-1997 & planctônico \\
Lago das Garças & SP255752 & $18-$ VII-1991 & planctônico \\
Lago das Ninféias & SP294899 & $07-X I-1996$ & epifítico \\
Lago do Monjolo & SP294900 & $07-X I-1996$ & planctônico \\
Córrego Pirarunguá & SP294909 & $01-$ III-1997 & epifítico \\
& SP255749 & 18 -VII-1991 & epifítico \\
\hline
\end{tabular}




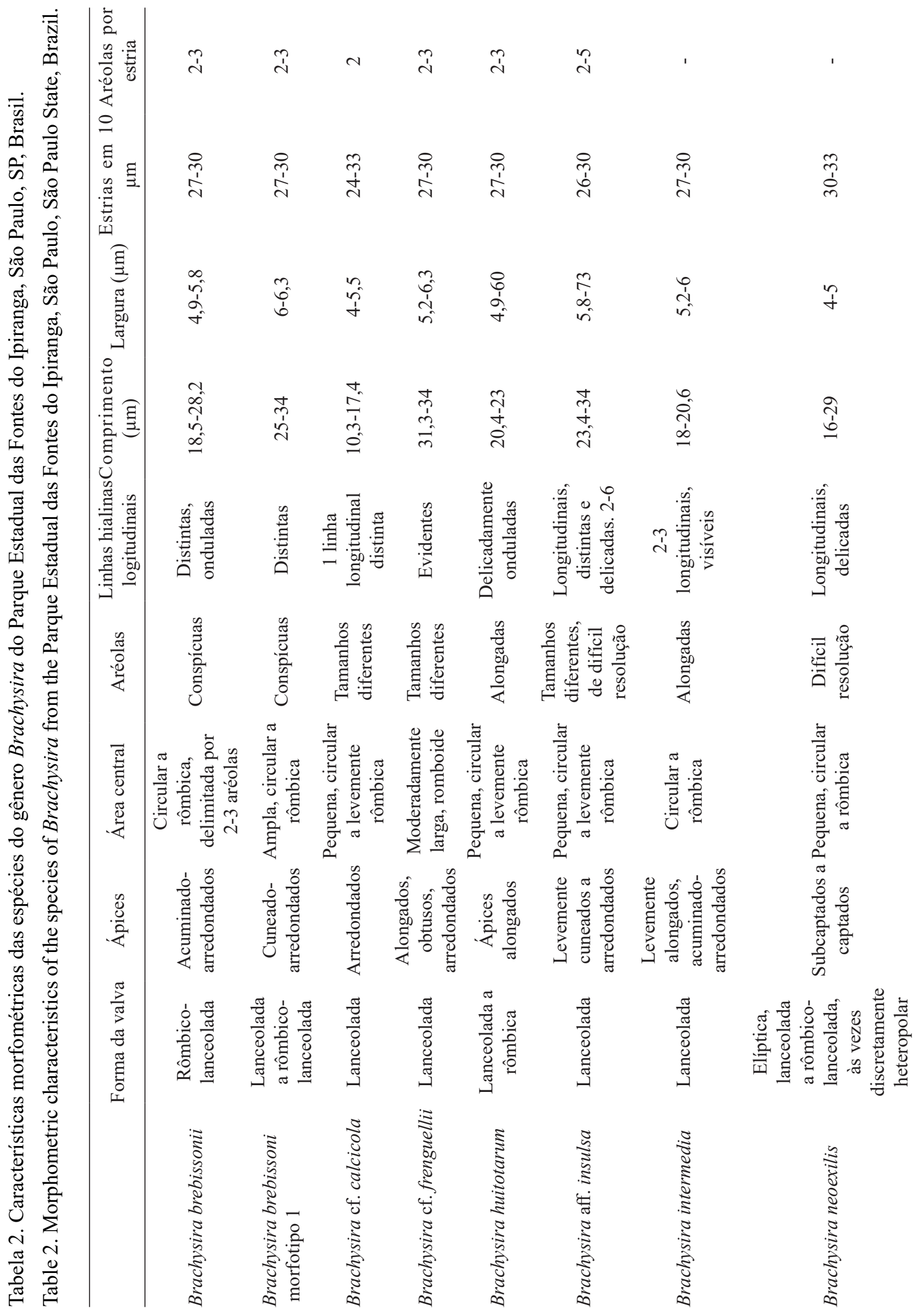




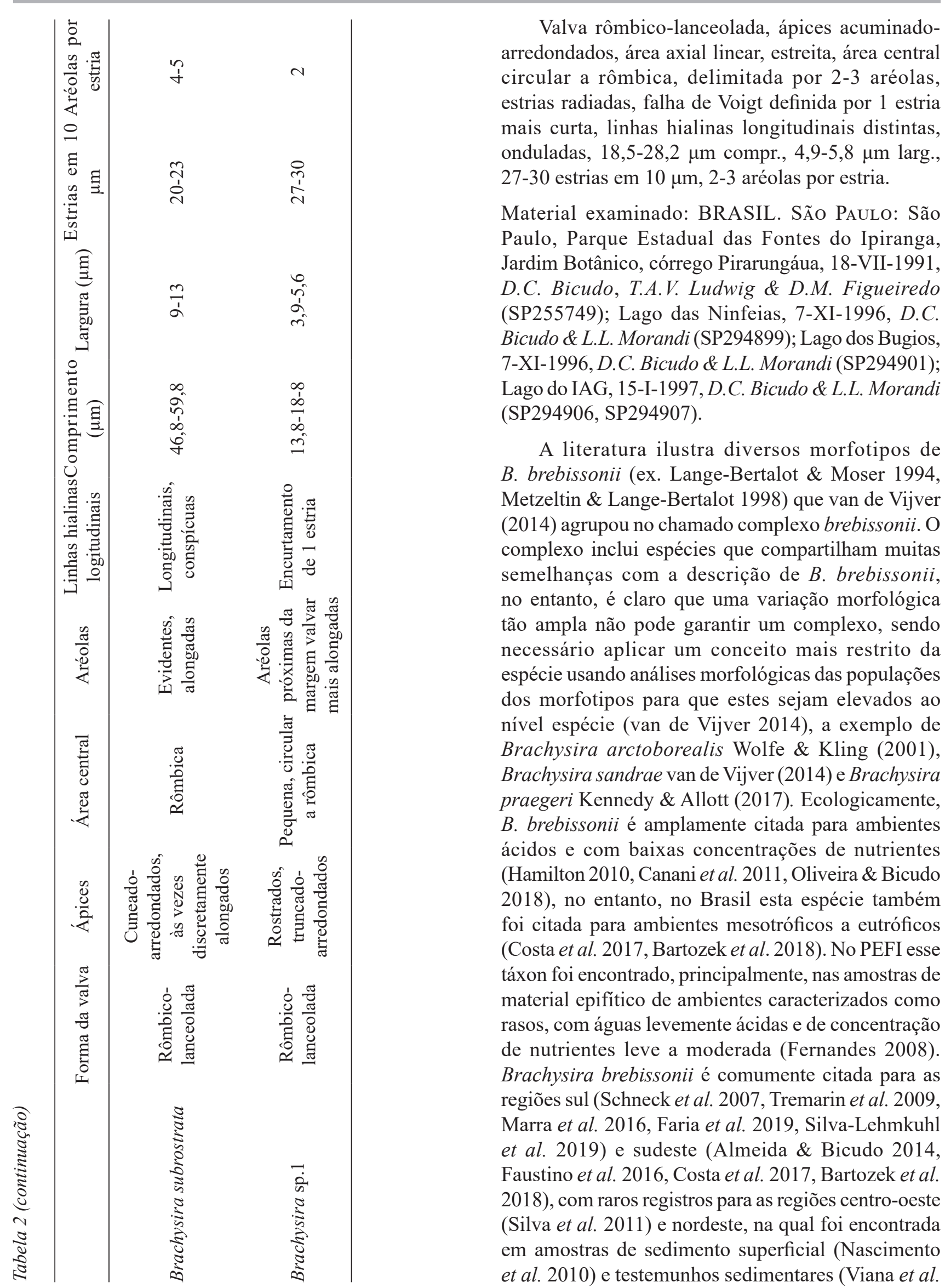


2014), para a região norte do Brasil não há registros deste táxon.

\section{Brachysira brebissonii Ross morfotipo 1}

Figuras 12-17

Valva lanceolada a rômbico-lanceolada, ápices cuneado-arredondados, área axial linear, estreita, área central ampla, circular a rômbica, estrias radiadas, aréolas conspícuas, falha de Voigt distinta, linhas hialinas longitudinais, distintas, 25-34 $\mu \mathrm{m}$ compr., 6,0-6,3 $\mu \mathrm{m}$ larg., 27-30 estrias em $10 \mu \mathrm{m}, 2-3$ aréolas por estria.

Material examinado: BRASIL. SÃo PAUlo: São Paulo, Parque Estadual das Fontes do Ipiranga, Lago do IAG, 15-I-1997, D.C. Bicudo \& L.L. Morandi (SP294906).

Optamos por identificar o atual material como B. brebissonii morfotipo 1 por apresentar contorno valvar semelhante ao do material-tipo de $B$. brebissonii Ross, porém, com algumas diferenças como valvas relativamente mais lanceoladas, área central mais ampla e medidas valvares maiores do que $B$. brebissonii (compr. 18,2-27,7 $\mu \mathrm{m}$, larg. 4,9-5,8 $\mu \mathrm{m}$ ), assemelhando-se à população de $B$. brebissonii ssp. brebissonii em Lange-Bertalot \& Moser (1994: pl. 44, fig. 1-10). Estas características permitem, consequentemente, considerar esse morfotipo como pertencente ao complexo-brebissonii 'sensu' van de Vijver (2014). Pode ser comparada também com Brachysira krammeri Lange-Bertalot, no entanto, a última espécie apresenta menor densidade de estrias (22-24 em $10 \mu \mathrm{m})$ e área axial comparativamente mais ampla. Neste estudo, este morfotipo ocorreu com hábito epifítico no Lago do IAG, que é a única represa do Parque que possui condições oligotróficas (Bicudo et al. 2002, Vercellino \& Bicudo 2006).

** Brachysira cf. calcicola Lange-Bertalot. Bibliotheca Diatomologica 29: 23, pl. 41, fig. 19-33. 1994.

Figuras 18-29

Valva lanceolada, ápices arredondados, área axial linear, estreita, área central pequena, circular, a levemente rômbica, estrias levemente radiadas, aréolas de tamanhos diferentes, falha de Voigt definida por 1 estria mais curta, 1 linha longitudinal distinta, 10,3-17,4 $\mu \mathrm{m}$ compr., 4-5,5 $\mu \mathrm{m}$ larg., 24-33 estrias em $10 \mu \mathrm{m}, 2$ aréolas por estria.

Material examinado: BRASIL. São PAulo: São Paulo, Parque Estadual das Fontes do Ipiranga, Jardim
Botânico, hidrofitotério, 18-VII-1991, D.C. Bicudo, T.A.V. Ludwig \& D.M. Figueiredo (SP255745); 7-XI-1996, D.C. Bicudo \& L.L. Morandi (SP294903), 12-IV-2017, S.A. Oliveira, K.S. Morais \& C.E.M. Bicudo (SP469783); Lago dos Bugios, 18-VII-1991, D.C. Bicudo, T.A.V. Ludwig \& D.M. Figueiredo (SP255747, SP255748); 7-XI-1996, D.C. Bicudo \& L.L. Morandi (SP294902); Lago das Garças, 18-VII-1991, D.C. Bicudo, T.A.V. Ludwig \& D.M. Figueiredo (SP255752); Lago do IAG, 15-I-1997, D.C. Bicudo \& L.L. Morandi (SP294906, SP294907).

A atual população de $B$. cf. calcicola apresenta menor densidade de estrias do que a apresentada pela população tipo (24-33 vs. 32-34 estrias em $10 \mu \mathrm{m}$ ). Por este motivo, optamos por identificar os presentes exemplares com certa dúvida: Brachysira cf. calcicola. A espécie é citada para ambientes oligotróficos, calcários, com moderada concentração de eletrólitos e sempre alcalinos (Lange-Bertalot \& Moser 1994). Esta espécie assemelha-se a Brachysira huitotarum Vouilloud et al. no formato da valva, no entanto, diferem no maior comprimento $(17,0-28,5 \mu \mathrm{m})$, ápices evidentemente sub-rostrados, áreas hialinas delicadas e estrias radiadas em $B$. huitotarum. Diferente de $B$. calcicola, $B$. huitotarum foi registrado para ambientes levemente ácidos e com baixas condutividade e transparência (Vouilloud et al. 2014). Brachysira cf. calcicola foi encontrada em lagos rasos com alta densidade de macrófitas, no epifíton e no plâncton. O presente registro é o primeiro da ocorrência da espécie no Brasil.

** Brachysira cf. frenguellii (Manguin) LangeBertalot \& Moser. Bibliotheca Diatomologica 29: 28. 1994. $\equiv$ Anomoeoneis frenguellii Manguin in Bourrelly \& Manguin, Algues d'eau douce de la Guadeloupe et dépendances: recueillies par la Mission P. Allorge en 1936. c. 1952.

Figuras 30-35

Valva lanceolada, ápices alongados, obtusos, arredondados, área axial linear, estreita, área central moderadamente larga, romboide, estrias radiadas, falha de Voigt inconspícua, linhas hialinas, longitudinais, evidentes, 31,3-34,0 $\mu \mathrm{m}$ compr., 5,2-6,3 $\mu \mathrm{m}$ larg., 27-30 estrias em $10 \mu \mathrm{m}, 2-3$ aréolas por estria.

Material examinado: BRASIL. SÃo PAULO: São Paulo, Parque Estadual das Fontes do Ipiranga, Lago do IAG, 15-I-1997, D. C. Bicudo \& L.L. Morandi (SP294906).

A descrição original de Anomoeoneis frenguellii Manguin propõe a espécie baseada em uma única 
ilustração (Bourrely \& Manguin 1952). LangeBertalot \& Moser (1994) propuseram a transferência da espécie para Brachysira frenguellii. Treze anos mais tarde, Metzeltin \& Lange-Bertalot (2007) também propuseram nova combinação para $A$. frenguellii, como $B$. frenguellii (ilegítima) e forneceram ilustrações algumas das quais em microscopia óptica. Ainda se questiona se $B$. frenguellii é, fato, um táxon independente, um morfotipo de $B$. brebissonii (Lange-Bertalot \& Moser 1994) ou se trata de um híbrido de $B$. brebissonii $\times$ Brachysira neoexilis Lange-Bertalot (Metzeltin \& Lange-Bertalot 2007). Como ainda paira dúvida sobre seu reconhecimento como espécie, optamos por deixar a identificação como Brachysira cf. frenguellii. A população estudada apresentou medidas menores do que as divulgadas por Manguin (1952, como A. frenguellii Manguin: compr. 35-38 $\mu \mathrm{m}$, larg. 7,0-7,5 $\mu \mathrm{m}$ ) e Metzeltin \& Lange-Bertalot (2007, como B. frenguellii: compr. 31,0-32,5 $\mu \mathrm{m}$, larg. 6,0-6,5 $\mu \mathrm{m})$. Brachysira frenguellii lembra Brachysira linearilanceolata Metzeltin \&
Lange-Bertalot no formato valvar (compr. 39-47 $\mu \mathrm{m}$, larg. 7,3-8,7 $\mu \mathrm{m})$ e Brachysira krammeri LangeBertalot (compr. 17-55 $\mu \mathrm{m}$, larg. 5-8 $\mu \mathrm{m}$ ), mas $B$. linearilanceolata possui aréolas e rafe mais grosseiras e B. krammeri apresenta ápices mais apiculados. No presente trabalho, este material foi encontrado vivendo como epifítico em ambiente raso e oligotrófico. O presente é o primeiro registro da presença da espécie no Brasil.

** Brachysira huitotarum Vouilloud, Sala \& NúñezAvellaneda. Diatom Research 29(2): 152, fig. 15-28. 2014.

Figuras 36-52

Valva lanceolada a rômbica, ápices alongados, subrostrados, arredondados, área axial linear, estreita, área central pequena, circular a levemente rômbica, aréolas mais alongadas, estrias radiadas, falha de Voigt identificada por 1 estria mais curta, linhas hialinas longitudinais delicadamente onduladas, 20,4-23,0 $\mu \mathrm{m}$ compr., 4,9-6,0 $\mu \mathrm{m}$ larg., 27-30 estrias em $10 \mu \mathrm{m}, 2-3$ aréolas por estria.
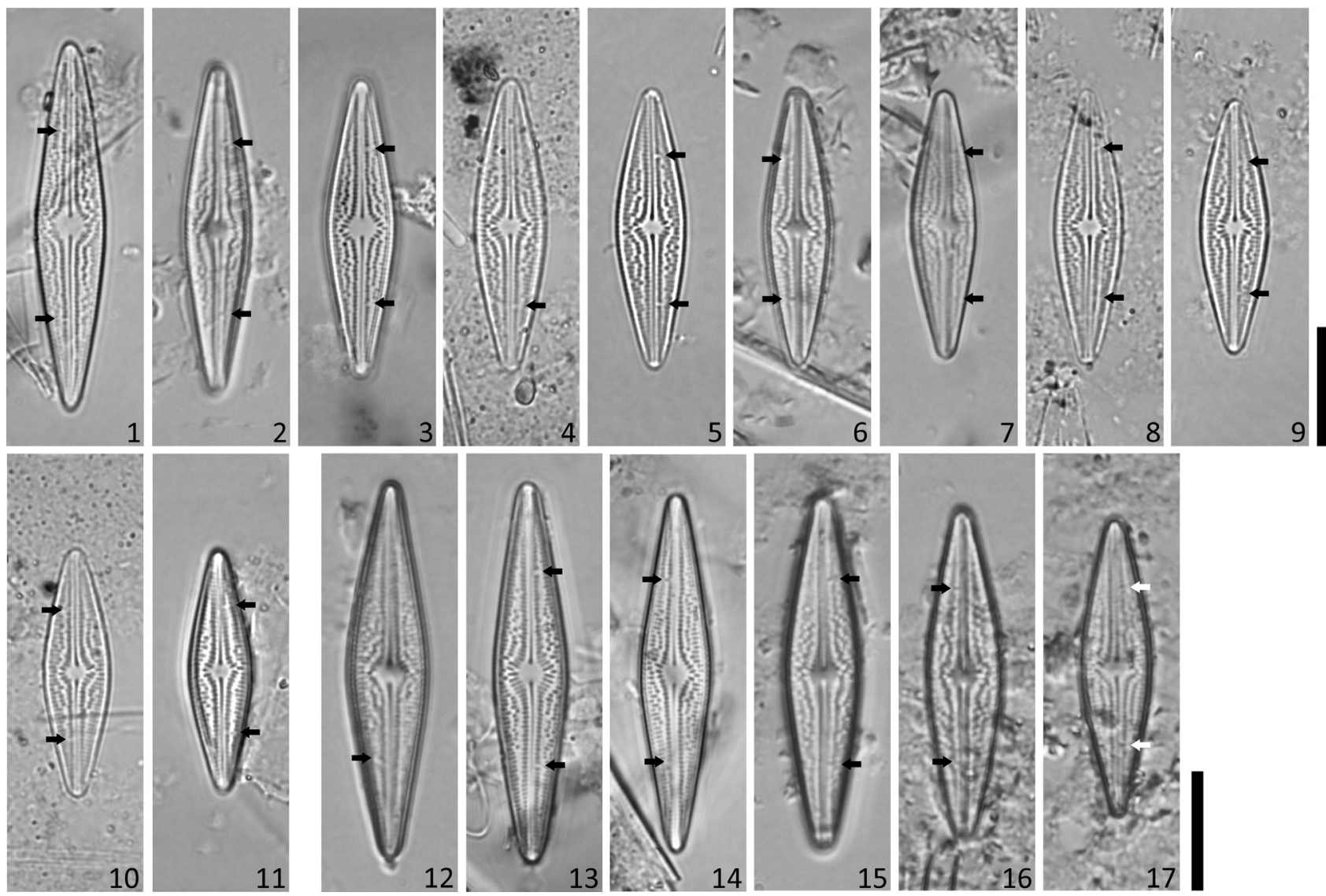

Figuras 1-17. Representantes de Brachysira. 1-11. Brachysira brebissonii Ross. 12-17. Brachysira brebissonii Ross Morfotipo 1. Falha de Voigt (seta). Barra de escala $=10 \mu \mathrm{m}$.

Figures 1-17. Brachysira species. 1-11. Brachysira brebissonii Ross. 12-17. Brachysira brebissonii Ross Morphotype 1. Voigt discontinuity (arrow). Scale bar $=10 \mu \mathrm{m}$. 

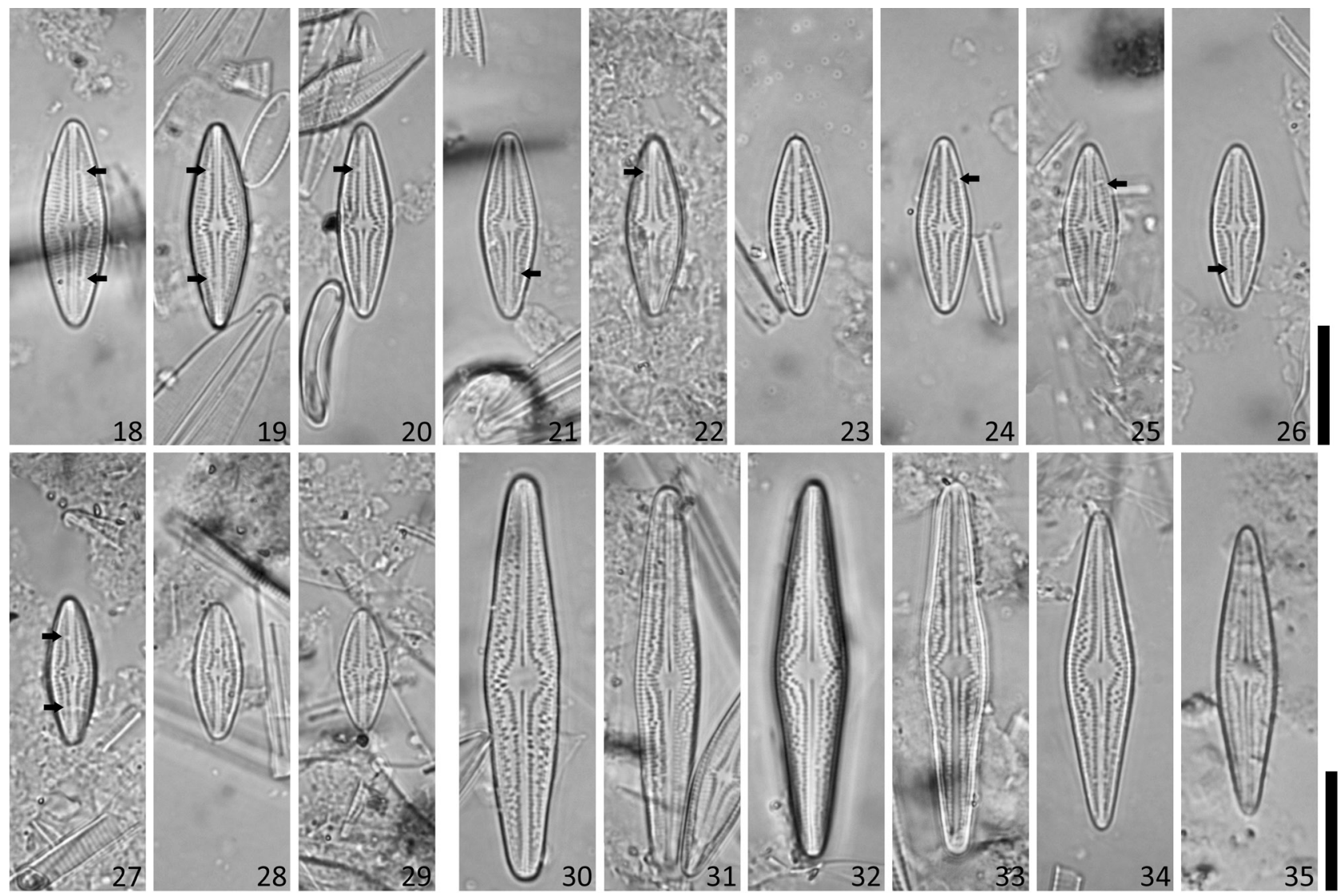

Figuras 18-35. Representantes de Brachysira. 18-29. Brachysira cf. calcicola Lange-Bertalot. 30-35. Brachysira cf. frenguellii (Manguin) Lange-Bertalot \& Moser. Falha de Voigt (seta). Barra de escala $=10 \mu \mathrm{m}$.

Figures 18-35. Brachysira species. 18-29. Brachysira cf. calcicola Lange-Bertalot. 30-35. Brachysira cf. frenguellii (Manguin) LangeBertalot \& Moser. Voigt discontinuity (arrow). Scale bar $=10 \mu \mathrm{m}$.

Material examinado: BRASIL. São PAUlo: São Paulo, Parque Estadual das Fontes do Ipiranga, Jardim Botânico, Lago dos Bugios, 18-VII-1991, D.C. Bicudo, T.A.V. Ludwig \& D.M. Figueiredo (SP255747).

Brachysira huitotarum difere de B. brebissonii por apresentar ápices relativamente mais alongados e sub-rostrados, área central delimitada por aréolas mais alongadas, linhas hialinas mais delicadas e maior densidade de estrias. Foi citada como uma espécie perifítica em rios da Amazônia Colombiana, com $\mathrm{pH}$ levemente ácido $(5,3-6,6)$ e baixa condutividade (12,0-33,3 $\mu \mathrm{S} \mathrm{cm}^{-1}$ ) (Vouilloud et al. 2014). No presente trabalho, foi registrada com hábito epifítico para o Lago dos Bugios, caracterizado como raso, com águas ácidas e pobre em nutrientes (Fernandes 2008). Esta é a primeira citação da ocorrência da espécie no Brasil.

Brachysira aff. insulsa Metzeltin \& Lange-Bertalot. Iconographia Diatomologica 5: 24, pl. 107, fig. 1-4. 1998.

Figuras 53-58
Valva lanceolada, ápices levemente cuneados a arredondados, área axial linear, estreita, área central pequena, circular a levemente rômbica, estrias radiadas, aréolas de tamanhos diferentes, difícil resolução, falha de Voigt distinta pelo encurtamento de 1 estria, às vezes inconspícua, 2-6 linhas hialinas, longitudinais, distintas, delicadas, 23,4-34,0 $\mu \mathrm{m}$ compr., 5,8-7,3 $\mu \mathrm{m}$ larg., 26-30 estrias em $10 \mu \mathrm{m}, 2-5$ aréolas por estria.

Material examinado: BRASIL. São PAULo: São Paulo, Parque Estadual das Fontes do Ipiranga, Jardim Botânico, Lago dos Bugios, 18-VII-1991, D.C. Bicudo, T.A.V. Ludwig \& D.M. Figueiredo (SP255748); córrego Pirarungáua, 18-VII-1991, D.C. Bicudo, T.A.V. Ludwig \& D.M. Figueiredo (SP255750); Lago do Monjolo, 1-III-1997, D.C. Bicudo, T.A.V. Ludwig \& L.L. Morandi (SP294909).

Brachysira insulsa Metzeltin \& Lange-Bertalot apresenta valvas levemente 3 -onduladas e medidas do comprimento pouco maiores $(29-36 \mu \mathrm{m})$ do que as da 
população coletada no PEFI, falha de Voigt sempre visível e 3-4 linhas hialinas longitudinais (Metzeltin \& Lange-Bertalot 1998). Entretanto, essas populações assemelham-se no que se refere aos formatos das áreas axial e central e à largura da valva. O material tipo de Brachysira insulsa não traz detalhes sobre o local de coleta, e a referência para localidade-tipo é dada como "Fossil BRASILIEN", devido à ausência de informações sobre a localização geográfica exata da amostra tipo, optamos por limitar o registro da população encontrada nesse estudo como sendo a primeira menção à sua ocorrência no PEFI, a qual foi encontrada em amostras epifíticas e planctônicas.

** Brachysira intermedia (Østrup) Lange-Bertalot. Bibliotheca Diatomologica 29: 34, pl. 48, fig. 1-7. 1994.

Figuras 59-64

Valva lanceolada, ápices levemente alongados, acuminado-arredondados, área axial estreita, linearlanceolada, área central circular a rômbica, estrias radiadas, aréolas alongadas, falha de Voigt distinta pelo encurtamento de 1 estria, 2-3 linhas hialinas, longitudinais, visíveis, 18,0-20,6 $\mu \mathrm{m}$ compr., 5,2-6,0 $\mu \mathrm{m}$ larg., 27-30 estrias em $10 \mu \mathrm{m}$.

Material examinado: BRASIL. São PAUlo: São Paulo, Parque Estadual das Fontes do Ipiranga, Jardim Botânico, Lago dos Bugios, 7-XI-1996, D.C. Bicudo \& L.L. Morandi (SP294901); Lago do IAG, 15-I-1997, D.C. Bicudo \& L.L. Morandi (SP294906).

O contorno valvar de $B$. intermedia lembra o de Brachysira sandrae, mas esta apresenta aréolas de tamanhos desiguais e distribuídas heterogeneamente (van de Vijver 2014). Brachysira brebissonii difere de $B$. intermedia por apresentar ápices não alongados e contorno valvar rômbico-lanceolado. A população deste estudo assemelha-se à de Brachysira aff. intermedia em Kennedy \& Allott (2017) e também à de Lange-Bertalot \& Moser (1994). No passado, $B$. intermedia não era independente de $B$. brebissonii, razão pela qual sua ecologia e distribuição geográfica ainda são pouco conhecidas (Cantonati et al. 2017). Todavia, a espécie é citada para rios (Leira et al. 2017) e ambientes oligotróficos com poucos eletrólitos (Cantonati et al. 2017). Neste trabalho, a espécie foi encontrada com hábito epifítico no Lago do IAG e no Lago dos Bugios, ambos rasos, com águas ácidas e pouco nutrientes (Bicudo et al. 2002, Fernandes 2008). $O$ presente é o primeiro registro da ocorrência de $B$. intermedia no Brasil.
Brachysira neoexilis Lange-Bertalot. Bibliotheca Diatomologica 29:51, pl. 5, fig. 1-35, pl.6, fig. 1-6, pl. 17, fig. 7-11, pl. 32, fig. 27-30, pl. 46, fig. 19-27. 1994.

Figuras 65-82

Valva elíptica, lanceolada a rômbico-lanceolada, podendo apresentar discreta heteropolaridade, ápices rostrados, subcapitados a capitados, área axial linear, estreita, área central pequena, circular a rômbica, estrias radiadas, aréolas de difícil resolução, falha de Voigt não distinguível, linhas hialinas, longitudinais, delicadas, 16,0-29,0 $\mu \mathrm{m}$ compr., 4,0-5,0 $\mu \mathrm{m}$ larg., 30-33 estrias em $10 \mu \mathrm{m}$.

Material examinado: BRASIL. São PAulo: São Paulo, Parque Estadual das Fontes do Ipiranga, Jardim Botânico, hidrofitotério, 18-VII-1991, D.C. Bicudo, T.A.V. Ludwig \& D.M. Figueiredo (SP255745); 7-XI-1996, D.C. Bicudo \& L.L. Morandi (SP294903); 12-IV-2017, S.A. Oliveira, K.S. Morais \& C.E.M. Bicudo (SP469783); Lago dos Bugios, 18-VII-1991, D.C. Bicudo, T.A.V. Ludwig \& D.M. Figueiredo (SP255747); 7-XI-1996, D.C. Bicudo \& L.L. Morandi (SP294902); Lago das Ninfeias, 7-XI-1996, D.C. Bicudo \& L.L. Morandi (SP294899, SP294900); Lago do IAG, 15-I-1997, D.C. Bicudo \& L.L. Morandi (SP294906, SP294907).

Brachysira neoexilis compartilha muitas semelhanças com Brachysira microcephala (Kützing) Compère, o que faz com que alguns autores (Wolfe \& Kling 2001, Shayler \& Siver 2004a) não aceitem diferenciá-las e considerem B. microcephala o nome que deve prevalecer sobre $B$. neoexilis. Entretanto, Cantonati et al. (2017) discordaram da proposta de Lange-Bertalot \& Moser (1994) argumentando tratar-se de duas espécies diferentes que, apesar da sobreposição de medidas, apresentam claras diferenças no formato da valva e dos ápices. Ambas as espécies diferenciam, principalmente, no formato dos ápices, alongados e capitados de $B$. microcephala (Hamilton 2010) e distintos, rostrados, subcapitados ou capitados em B. neoexilis (Lange-Bertalot \& Moser 1994). Também, na área central quase sempre indistinta da área axial em $B$. microcephala e distinta e circular em B. neoexilis. Alguns autores reconhecem, entretanto, morfotipos dentro da população (Wolfe \& Kling 2001, Shayler \& Siver 2004a, Kennedy \& Allott 2017). A presente população do PEFI apresentou indivíduos com ápices variando de rostrado a capitado e área central sempre distinta da área axial, diferente 

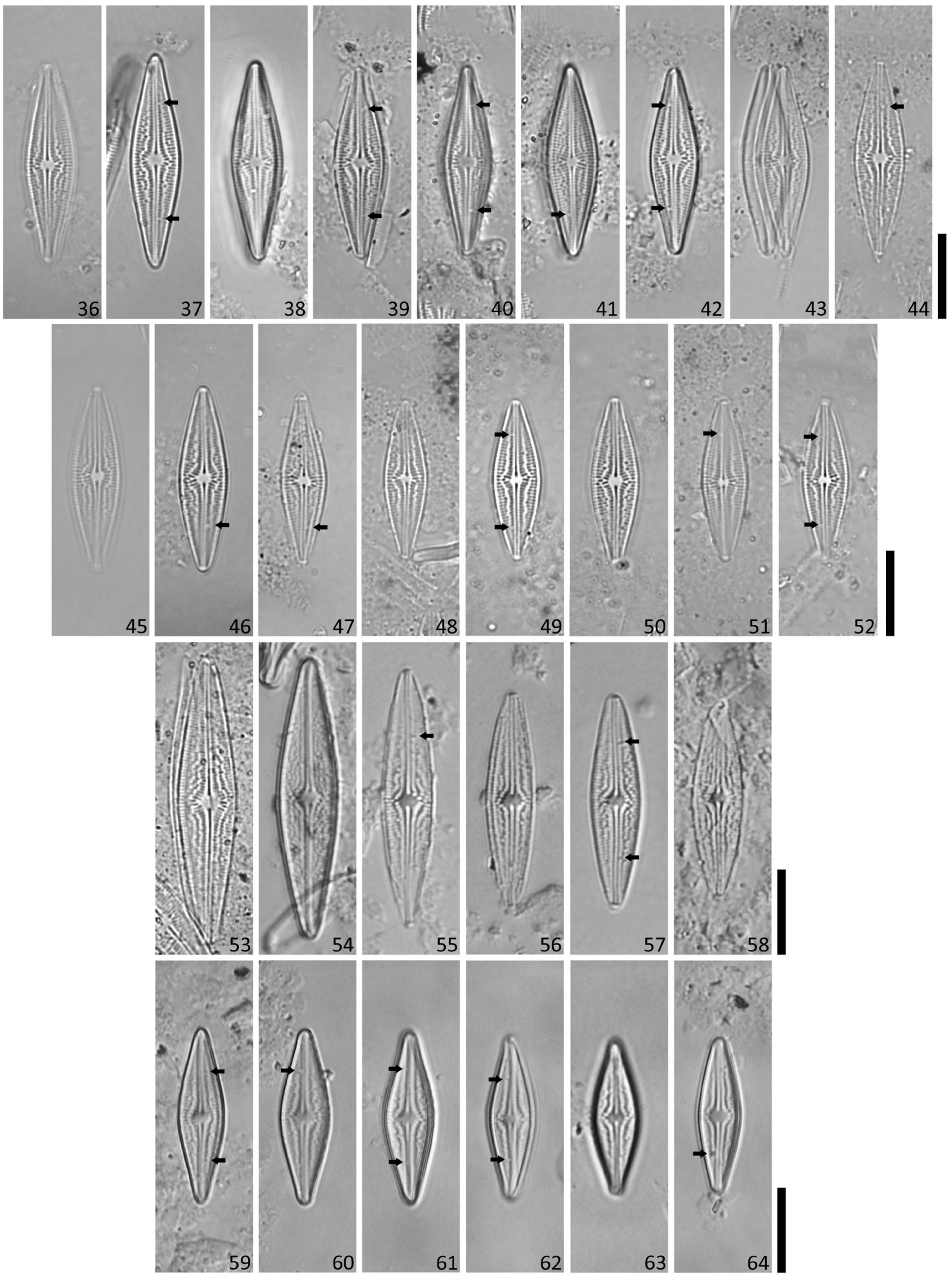

Figuras 36-64. Representantes de Brachysira. 36-52. Brachysira huitotarum Vouilloud, Sala \& Núñez-Avellaneda. 53-58. Brachysira aff. insulsa Metzeltin \& Lange-Bertalot. 59-64. Brachysira intermedia (Østrup) Lange-Bertalot. Falha de Voigt (seta). Barra de escala = $10 \mu \mathrm{m}$. Figures 36-64. Brachysira species. 36-52. Brachysira huitotarum Vouilloud, Sala \& Núñez-Avellaneda. 53-58. Brachysira aff. insulsa Metzeltin \& Lange-Bertalot. 59-64. Brachysira intermedia (Østrup) Lange-Bertalot. Voigt discontinuity (arrows). Scale bar $=10 \mu \mathrm{m}$. 
do descrito para $B$. microcephala que possui ápices alongados, capitados e área central pequena, circular e, muitas vezes, indistinta da área axial. Assim sendo, concordamos com a proposta de $B$. neoexilis constituir uma espécie independente sustentada por LangeBertalot \& Moser (1994) e Cantonati et al. (2017). No Brasil, B. neoexilis foi registrada em reservatórios mesotróficos das regiões sudeste e sul (Bertolli et al. 2010, Almeida \& Bicudo 2014, Marra et al. 2016) e em um trabalho de levantamento das espécies de diatomáceas para o centro-oeste brasileiro (Silva et al. 2011). No presente estudo, ocorreu com hábitos planctônico e epifítico em ambientes rasos, variando de oligotrófico à mesotrófico (Bicudo et al. 2002, Fernandes 2008).

\section{Brachysira sp. 1}

Figuras 83-90

Valva rômbico-lanceolada, ápices rostrados, truncado-arredondados, área axial estreita, lanceolada, área central pequena, circular a rômbica, estrias transapicais radiadas, aréolas próximas da margem valvar mais alongadas, falha de Voigt sutil, formada pelo encurtamento de 1 estria, 1 linha hialina, longitudinal, conspícua, 13,8-18,8 $\mu \mathrm{m}$ compr., 3,9-5,6 $\mu \mathrm{m}$ larg., 27-30 estrias em $10 \mu \mathrm{m}, 2$ aréolas por estria.

Material examinado: BRASIL. São PAUlo: São Paulo, Parque Estadual das Fontes do Ipiranga, Jardim Botânico, córrego Pirarungáua, 18-VII-1991, D.C. Bicudo, T.A.V.Ludwig \& D.M. Figueiredo (SP255749); Lago dos Bugios, 18-VII-1991, D.C. Bicudo, T.A.V. Ludwig \& D.M. Figueiredo (SP255748); 7-XI-1996, D.C. Bicudo \& L.L. Morandi (SP294901); Lago das Ninfeias, 7-XI-1996, D.C. Bicudo \& L.L. Morandi (SP294899).

Brachysira sp. 1 ocorreu em amostras epifíticas e planctônicas em ambientes rasos variando de oligotrófico a mesotrófico (Bicudo et al. 2002, Fernandes 2008). Morfologicamente, assemelha-se no formato dos ápices e da área central, no padrão de estriação e nas medidas (compr. 13-17 $\mu \mathrm{m}$, larg. 4-6 $\mu \mathrm{m}, 29$ estrias em $10 \mu \mathrm{m}$ ) aos representantes da população em Metzeltin \& Lange-Bertalot (2007: pl. 171, fig. 26-29) identificada como Brachysira spec. No entanto, a população deste estudo apresentou valvas mais lanceoladas do que a população em Metzeltin \& Lange-Bertalot. Não há outros táxons dentro do gênero que se assemelhem ao presente material. Brachysira sp. 1 ocorreu junto com B. brebissonii, da qual difere claramente pelo contorno valvar, principalmente, nos ápices valvares, que nunca são rostrados em B. brebissonii. Brachysira sp. 1 ocorreu epífita e planctônica em ambientes rasos, variando de oligo a mesotróficos (Bicudo et al. 2002, Fernandes 2008).

* Brachysira subrostrata Lange-Bertalot. Bibliotheca Diatomologica 29: 68, pl. 35, fig. 7-11, pl. 36, fig. 9. 1994.

Figuras 91-102

Valva rômbico-lanceolada, ápices cuneadoarredondados, às vezes discretamente alongados, área axial variável, podendo ser estreita ou amplamente lanceolada, área central rômbica, estrias transapicais radiadas, aréolas alongadas, bem evidentes, falha de Voigt evidente por 1 separação entre as estrias, linhas hialinas, longitudinais, conspícuas, 46,8-59,8 $\mu \mathrm{m}$ compr., 9,0-13,0 $\mu \mathrm{m}$ larg., 20-23 estrias em $10 \mu \mathrm{m}$, 4-5 aréolas por estria.

Material examinado: BRASIL. São PAulo: São Paulo, Parque Estadual das Fontes do Ipiranga, Jardim Botânico, hidrofitotério, 18-VII-1991, D.C. Bicudo, T.A.V. Ludwig \& D.M. Figueiredo (SP255745); 7-XI-1996, D.C. Bicudo \& L.L. Morandi (SP294903); 12-IV-2017, S.A. Oliveira, K.S. Morais \& C.E.M. Bicudo (SP469783); Lago das Garças, 18-VII-1991, D.C. Bicudo, T.A.V. Ludwig \& D.M. Figueiredo (SP255752); Lago dos Bugios, 7-XI-1996, D.C. Bicudo \& L.L. Morandi (SP294902); Lago do IAG, 15-I-1997, D.C. Bicudo \& L.L. Morandi (SP294906, SP294907).

Brachysira subrostrata foi proposta a partir de fotomicrografias em microscopia de luz de espécimes encontrados com hábito epifítico em amostras do Brasil (Lange-Bertalot \& Moser 1994). Vouilloud et al. (2014) encontraram a espécie na Amazônia Colombiana e efetuaram o primeiro registro da ultraestrutura das valvas da espécie ao microscópio eletrônico de varredura. Brachysira subrostrata é morfologicamente semelhante a $B$. serians (Brébisson) Round \& Mann, mas esta é proporcionalmente mais larga $(14,0-19,0 \mu \mathrm{m})$ e apresenta a falha de Voigt evidente (Lange-Bertalot \& Moser 1994). Brachysira superserians Metzeltin \& Lange-Bertalot e B. macroserians Metzeltin \& Lange-Bertalot também são semelhantes a $B$. subrostrata no que tange ao contorno valvar, mas apresentam medidas do comprimento $(145,0-165,0 \mu \mathrm{m}$ e $75,0-96,0 \mu \mathrm{m}$, respectivamente) e da largura $(26,0-28,0 \mu \mathrm{m}$ e $17,0-20,0$ $\mu \mathrm{m}$, respectivamente) bem superiores às registradas para $B$. subrostrata. Espécies morfologicamente 


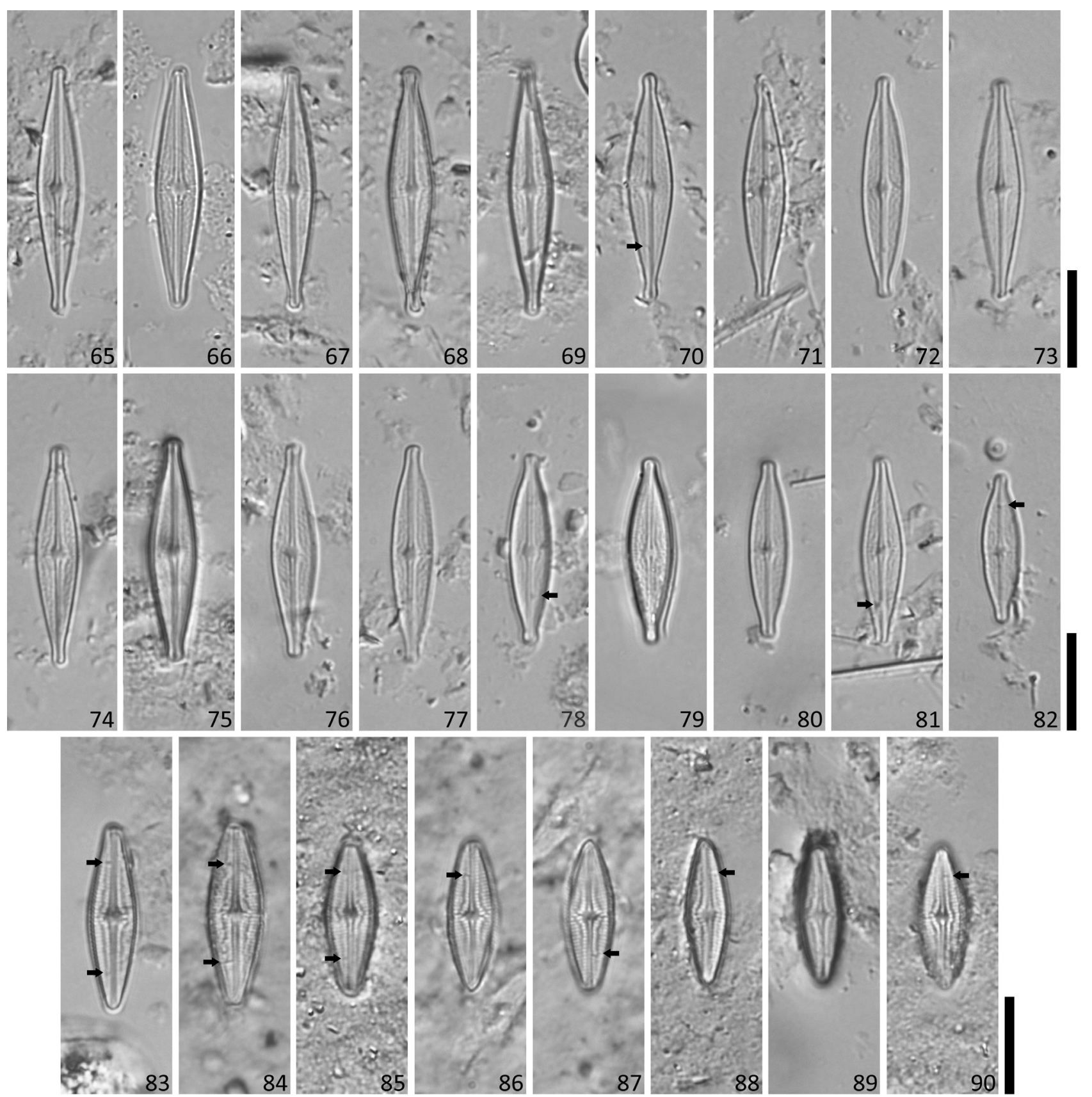

Figuras 65-90. Representantes de Brachysira. 65-82. Brachysira neoexilis Lange-Bertalot. 83-90. Brachysira sp. 1. Falha de Voigt (seta). Barra de escala $=10 \mu \mathrm{m}$.

Figures 65-90. Brachysira species. 65-82. Brachysira neoexilis Lange-Bertalot. 83-90. Brachysira sp. 1. Voigt discontinuity (arrow). Scale bar $=10 \mu \mathrm{m}$.

semelhantes a $B$. subrostrata, mas com medidas menores, são Brachysira neoacuta Lange-Bertalot (compr. 40,0-65,0 $\mu \mathrm{m}$, larg. 6,0-9,0 $\mu \mathrm{m}$ ) e Brachysira microserians Metzeltin \& Lange-Bertalot (compr. 24,0-31,0 $\mu \mathrm{m}$, larg. 7,0-8,0 $\mu \mathrm{m}$ ). No Brasil, a espécie foi citada para região Sul (Lange-Bertalot \& Moser 1994, Tremarin et al. 2009, Canani et al. 2011) e para região centro-oeste (Silva et al. 2011). No presente estudo a espécie foi encontrada sobre hábito epifítico e planctônico, sendo o primeiro registro da presença de B. subrostrata no Estado de São Paulo.

\section{Considerações Finais}

O levantamento florístico do gênero Brachysira no PEFI registrou a presença de 10 táxons, contribuindo 

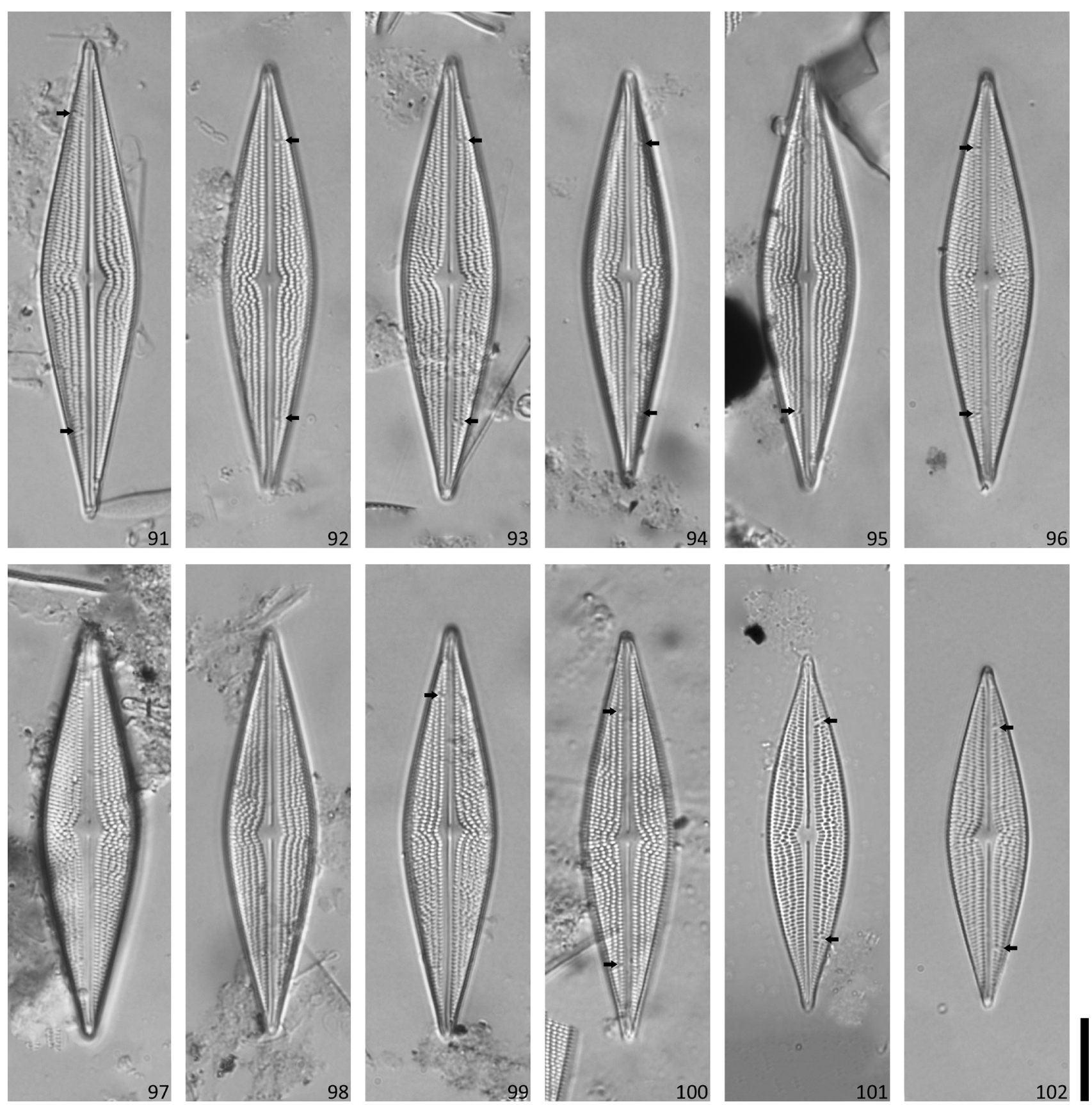

Figuras 91-102. Representantes de Brachysira. 91-102. Brachysira subrostrata Lange-Bertalot. Falha de Voigt (seta). Barra de escala $=10 \mu \mathrm{m}$.

Figures 91-102. Brachysira species. 91-102. Brachysira subrostrata Lange-Bertalot. Voigt discontinuity (arrow). Scale bar $=10 \mu \mathrm{m}$.

com uma nova citação para o Estado de São Paulo (B. subrostrata) e quatro novas citações para o Brasil (Brachysira cf. calcicola, Brachysira cf. frenguellii, Brachysira huitotarum e Brachysira intermedia). Incluiu também duas espécies já conhecidas (Brachysira brebissonii e Brachysira neoexilis), um morfotipo e um táxon identificado em nível gênero.
Brachysira é um gênero que merece avaliação mais crítica e cuidadosa nos trabalhos florísticos. Muitos espécimes tratados como morfotipos do complexo Brachysira são, possivelmente, novas espécies que necessitam de estudos morfológicos mais detalhados para possível confirmação. Embora as espécies do complexo brebissonii compartilhem muitas semelhanças entre si, uma identificação 
morfológica criteriosa seria suficiente para diferenciar as espécies do complexo. O presente trabalho mostra uma lacuna e a subamostragem deste grupo no Brasil. Sugere, finalmente, que se trata de um grupo com potencial para esclarecimentos morfológicos e da distribuição das espécies já conhecidas e, possivelmente, a descrição de novas espécies.

\section{Agradecimentos}

Os autores agradecem ao Programa de PósGraduação em Ciências Biológicas, Área Biologia Vegetal, Universidade Estadual Paulista, Rio Claro e ao Programa de Pós-Graduação em Biodiversidade Vegetal e Meio Ambiente, Instituto de Botânica, São Paulo; à FAPEAM (Fundação de Amparo à Pesquisa do Estado do Amazonas) pela bolsa de Doutorado concedida a AMSL (EDITAL N. 003/2015 RH-INTERIORIZAÇÃO) e EAL (EDITAL N. 010/2015 PROPG, AM); à CAPES (Coordenação de Aperfeiçoamento de Pessoal de Nível Superior) pelas bolsas de Doutorado concedidas a KSM e $\mathrm{SAO}$; ao CNPq, Conselho Nacional de Desenvolvimento Científico e Tecnológico pelas bolsas de produtividade concedidas a CEMB (Processo $n^{\circ}$ 305031/2016-3) e DCB (Processo n ${ }^{\circ} 310404 / 2016-9$ ).

\section{Literatura citada}

Almeida, P.D. \& Bicudo, D.C. 2014. Diatomáceas planctônicas e de sedimento superficial em represas de abastecimento da Região Metropolitana de São Paulo, SP, Sudeste do Brasil. Hoehnea 41: 187-207.

Anderson, K., Fate, M., Hsieh, C-H., Kim, L., Lazarus, K., Kociolek, J.P. \& Lowe, R. 2013. Algal diversity and the description of three new diatom (Bacillariophyta) species from Lake of the Clouds, Porcupine Mountains Wilderness State Park, Michigan, USA. The Michigan Botanist 52: 3-24.

Bartozek, E.C.R., Zorzal-Almeida, S. \& Bicudo, D.C. 2018. Surface sediment and phytoplankton diatoms across a trophic gradient in tropical reservoirs: new records for Brazil and São Paulo State. Hoehnea 45: 69-92.

Battarbee, R.W., Jones, V., Flower, R.J., Cameron, N., Bennion, H., Carvalho, L. \& Juggins, S. 2001. Diatoms. In: J.P. Smol, H.J.B. Birks \& W.M. Last (eds.). Tracking Environmental Change Using Lake Sediments. v. 3, Kluwer Academic Publishers, London, pp. 155-203.

Berg, A. 1952. Eine Diatomeengcmeinsch an der schwedischen Ostküste. Arkiv för Botanik 2: 1-39.
Bertolli, L.M., Tremarin, P.I. \& Ludwig, T.A.V. 2010. Diatomáceas perifíticas em Polygonum hydropiperoides Michaux, reservatório do Passaúna, Região Metropolitana de Curitiba, Paraná, Brasil. Acta Botanica Brasilica 24: 1065-1081.

Bes, D., Ector, L., Torgan, L.C. \& Lobo, E.A. 2012. Composition of the epilithic diatom flora from a subtropical river, Southern Brazil. Iheringia: Série Botânica 67: 93-125.

Bicudo, C.E.M., Carmo, C.F., Bicudo, D.C., Henry, R., Pião, A.C.S., Santos, C.M. \& Lopes, M.R.M. 2002. Morfologia e morfometria de três reservatórios do PEFI. In: D.C. Bicudo, M.C. Forti \& C.E.M. Bicudo (orgs.). Parque Estadual das Fontes do Ipiranga (PEFI): unidade de conservação que resiste à urbanização de São Paulo. Editora Secretaria do Meio Ambiente do Estado de São Paulo, São Paulo, pp. 133-142.

Bicudo, C.E.M. \& Menezes, M. 2017. Gêneros de algas de águas continentais do Brasil: chave para identificação de gêneros. 3 ed. RiMa Editora, São Carlos.

Canani, L.G.C., Menezes, M. \& Torgan, L.C. 2011. Diatomáceas epilíticas de águas oligotróficas e ácidas do Sudeste do Brasil. Acta Botanica Brasilica 25: 130-140.

Cantonati, M., Kelly, M.G. \& Lange-Bertalot, H. 2017. Freshwater benthic diatoms of Central Europe: over 800 common species used in ecological assessment. English edition with update taxonomy and added species. : Koeltz Botanical Books, Schmitten-Oberreifenberg, pp. 1-942.

Carneiro, L.A. \& Bicudo, D.C. 2007. O gênero Lemnicola (Bacillariophyceae) no Estado de São Paulo, Brasil. Hoehnea 34: 253-259.

Costa, L.F., Wengrat, S. \& Bicudo, D.C. 2017. Diatoms from distinct habitats of a highly heterogeneous reservoir, Billings Complex, southeastern Brazil. Hoehnea 44: 559-579.

Ehrlich, A. 1978. The diatoms of the hyperhaline Solar Lake (NE Sinai). Israel Journal of Botany 27: 1-13.

Faria, D.M., Costin, J.C., Tremarin, P.I. \& Ludwig, T.A.V. 2019. Temporal changes in biological traits of diatom communities in response to an oil spill in a subtropical river. An Acad Bras Cienc 91: e20170863.

Faustino, S.B., Fontana, L., Bartozek, E.C.R., Bicudo, C.E.M. \& Bicudo, D.C. 2016. Composition and distribution of diatom assemblages from core and surface sediments of a water supply reservoir in Southeastern Brazil. Biota Neotropica 16: e20150129.

Fernandes, S. 2008. Sistemas hídricos do Jardim Botânico do Estado de São Paulo: uma experiência em educação para o ambiente. Annablume, São Paulo.

Ferreira, K.S.M. \& Bicudo, C.E.M. 2017. Criptógamos do Parque Estadual das Fontes do Ipiranga, São Paulo, SP. Algae, 42: Bacillariophyceae (Surirellales). Hoehnea 44: $10-28$. 
Guiry, M.D. \& Guiry, G.M. 2019. AlgaeBase: Worldwide electronic publication, National University of Ireland, Galway. Disponível em http://www.algaebase. org (acesso em 13-II-2019).

Hamilton, P. 2010a. Brachysira brebissonii. In: Diatoms of North America. Disponível em https://diatoms. org/species/brachysira_brebissonii (acesso em 05-VIII-2019).

Hamilton, P. 2010b. Brachysira microcephala. In: Diatoms of North America. Disponível em https://diatoms. $\mathrm{org} / \mathrm{species} /$ brachysira_microcephala (acesso em: 13-II-2019).

Hartley, B., Ross, R. \& Williams, D.M. 1986. A check-list of the freshwater, brackish and marine diatoms of the British Isles and adjoining coastal waters. Journal of the Marine Biological Association of the United Kingdom 66: 531-610.

Karayeva, N. \& Shevchenko, A.Y. 1974. On the methods of diatom algae investigation in scanning electron microscope. (In Russian). Botanichnyi Zhurnal 59: 988-991.

Kennedy, B. \& Allott, N. 2017. A review of the genus Brachysira in Ireland with the description of Brachysira praegeri and Brachysira conamarae, new raphid diatoms (Bacillariophyceae) from high status waterbodies. Phytotaxa 326: 1-27.

Kützing, F.T. 1836. Algarum aquae dulcis germanicarum Decas XVI. Halis Saxonum [Halle]: in commissis C.A. Schwetschkii et fil, pp. 1-25.

Kützing, F.T. 1844. Die kieselschaligen Bacillarien oder Diatomeen. Nordhausen, pp. 1-152.

Lange-Bertalot, H. \& Moser, G. 1994. Brachysira: Monographie der Gattung und Naviculadicta nov. gen. Bibliotheca Diatomologica 29: 1-212.

Leira, M., López-Rodríguez, M. del C. \& Carballeira, R. 2017. Epilithic diatoms (Bacillariophyceae) from running waters in NW Iberian Peninsula (Galicia, Spain). Anales del Jardín Botánico de Madrid 74: 1-24.

Marra, R.C., Tremarin, P.I.,Algarte, V.M. \& Ludwig, T.A. 2016. Epiphytic diatoms (Diatomeae) from Piraquara II urban reservoir, Paraná state. Biotaneotropica 16: e20160200.

Marquardt, G.C. \& Bicudo, C.E.M. 2014. Criptógamos do Parque Estadual das Fontes do Ipiranga, São Paulo, SP. Algas 36: Bacillariophyceae (Cymbellales). Hoehnea 41: 209-246.

Medlin, L.K. \& Kaczmarska, I. 2004. Evolution of diatoms, 5: morphological and cytological support for the major clade and a taxonomy revision. Phycologia 43: 245-270.

Metzeltin, D. \& Lange-Bertalot, H. 1998. Tropical diatoms of South America, 1: about 700 predominantly rarely known or new taxa representative of the neotropical flora. Iconographia Diatomologica 5: 1-695.
Metzeltin, D. \& Lange-Bertalot, H. 2007. Tropical diatoms of South America II. Special remarks on biogeography disjunction. Iconographia Diatomologica 18: 1-877.

Mora, D., Carmona, J., Jahn, R., Zimmermann, J. \& Abarca, N. 2017. Epilithic diatom communities of selected streams from the Lerma-Chapala Basin, Central Mexico, with the description of two new species. PhytoKeys 88: 39-69.

Morais, K.S., Oliveira, S.A., Lehmkuhl, E.A., SilvaLehmkuhl,A.M. \& Bicudo, C.E.M. 2019. Criptógamos do Parque Estadual das Fontes do Ipiranga, São Paulo, SP. Algae, 44: Bacillariophyceae (Surirelalles: Epithemia). Hoehnea 46: e262018.

Morandi, L.L., Ritter, L.M.O., Moro, R.S. \& Bicudo, C.E.M. 2006. Criptógamos do Parque Estadual do Ipiranga, São Paulo, SP. Algas, 20: Coscinodiscophyceae. Hoehnea 33: 115-122.

Moreira-Filho, H. \& Valente-Moreira, I.M. 1981. Avaliação taxonômica e ecológica das diatomáceas (Bacillariophyceae) epífitas em algas pluricelulares obtidas nos litorais dos Estados do Paraná, Santa Catarina e São Paulo. Boletim do Museu Botânico Municipal 47: 1-17.

Nascimento, L.R., Sifeddine, A., Torgan, L.C. \& Albuquerque, A.L.S. 2010. Diatom assemblage in a tropical lake of a northeastern Brazil. Brazilian Archives of Biology and Technology 53: 241-248.

Oliveira, S.A. \& Bicudo, C.E.M. 2018. Influence of environmental variables on the diatom communities of oligotrophic reservoirs for public water supply (Guarulhos, Southeast Brazil). Acta Limnologica Brasiliensia 30: e211.

Potapova, M.G., Hamilton, P.B., Kopyrina, L.I. \& Sosina, N.K. 2014. New and rare diatom (Bacillariophyta) species from a mountain lake in Eastern Siberia. Phytotaxa 156: 100-116.

Rocha, A.C.R. \& Bicudo, C.E.M. 2008. Criptógamos do Parque Estadual das Fontes do Ipiranga, São Paulo, SP. Algas, 25: Bacillariophyceae (Naviculales: Pinnulariaceae). Hoehnea 35: 597-618.

Round, F.E., Crawford, R.M. \& Mann, D.G. 1990. The diatoms: biology and morphology of the genera. Cambridge University Press, Cambridge.

Round, F.E. \& Mann, D.G. 1981. The diatom genus Brachysira I. Typification and separation from Anomoeoneis. Archiv für Protistenkunde 124: 221-231.

Santos, E.M., Tremarin, P.I. \& Ludwig, T.A.V. 2011. Diatomáceas perifíticas em Potamogeton polygonus Cham. \& Schltdl.: citações pioneiras para o estado do Paraná. Biota Neotropica 11: 303-315.

Schneck, F., Torgan, L.C \& Schwarzbold, A. 2007. Epilithic diatom community in high altitude stream impacted by fi shfarming in Southern Brazil. Acta Limnologica Brasiliensia 19: 341-355. 
Shayler, H.A. \& Siver, P.A. 2004a. Biodiversity of the genus Brachysira in the Ocala National Forest, Florida, U.S.A. In: Proceedings of the seventeenth international diatom symposium (Ed. by M. Poulin), Biopress Limited, Bristol, pp. 309-333.

Shayler, H.A. \& Siver, P.A. 2004b. Description of a new species of the diatom genus Brachysira (Bacillariophyta), Brachysira gravida sp. nov. from the Ocala National Forest, Florida, U.S.A. Nova Hedwigia 78: 399-409.

Silva-Lehmkuhl, A.M., Tremarin, P.I., Vercellino, I.S. \& Ludwig, T.A.V. 2019. Periphytic diatoms from an oligotrophic lenctic system, Piraquara I reservoir, Paraná state, Brazil. Biota Neotropica 19: e20180568.

Silva, A.M., Tremarin, P.I., Ludwig, T.A.V. \& Vercellino, I.S. 2010. Diatomáceas perifíticas em um sistema eutrófico brasileiro (Reservatório do Iraí, estado do Paraná). Acta Botanica Brasilica 24: 997-1016.

Silva, W.J., Nogueira, I.S. \& Souza, M.G.M. 2011. Catálogo de diatomáceas da região Centro-Oeste brasileira. Iheringia: Série Botânica 66: 61-86.

Simonsen, R. 1974. The diatom plankton of the Indian Ocean Expedition of R/V “Meteor", 1964-65 Meteor. Forschungsergebnisse Reihe D-Biologie 19: 1-66.

Souza, G.M.M. \& Compère, P. 1999. New diatoms species from the Federal District of Brazil. Diatom Research 14: 357-366.

Tremarin, P.I., Freire, E.G., Bertolli, L.M. \& Ludwig, T.A.V. 2009. Catálogo das diatomáceas (OchrophytaDiatomeae) continentais do estado do Paraná. Iheringia: Série Botânica 64: 79-107. van de Vijver, B. 2014. Analysis of the type material of Navicula brachysira Brébisson with the description of Brachysira sandrae, a new raphid diatom (Bacillariophyceae) from Iles Kerguelen (TAAF, sub-Antarctica, southern Indian Ocean). Phytotaxa 184: 139-147.

Vercellino, I.S. \& Bicudo, D.C. 2006. Sucessão da comunidade de algas perifíticas em reservatório oligotrófico tropical (São Paulo, Brasil): comparação entre período seco e chuvoso. Revista Brasileira Botânica 29: 363-377.

Viana, J.C.C., Sifeddine, A., Turcq, B., Albuquerque, A.L.S., Moreira, L.S., Gomes, D.F. \& Cordeiro, R.C. 2014. A late Holocene paleoclimate reconstruction from Boqueirão Lake sediments, northeastern Brazil. Palaeogeography, Palaeoclimatology, Palaeoecoly 415: 117-126.

Vouilloud, A.A., Sala, S.E., Núñez-Avellaneda, M., Montoya-Moreno, Y. \& Duque, S.R. 2014. Brachysira (Naviculales, Bacillariophyceae) in lowland waters from Colombia. Diatom Research 29: 147-162.

Werum, M. \& Lange-Bertalot, H. 2004. Diatoms in Springs from Central Europe and elsewhere under the influence of hydrologeology and anthropogenic impacts. Iconographia Diatomologica. A.R.G. Gantner Verlag Kommanditgesellschaft, Königstein, v. 13.

Witkowski, A.H., Lange-Bertalot, H. \& Metzeltin, D. 2000. Diatom flora of Marine Costs. Iconographia Diatomologica. A.R.G. Gantner Verlag Kommanditgesellschaft, Königstein, v. 7.

Wolfe, A.P. \& Kling, H.J. 2001. A consideration of some North American soft-water Brachysira taxa and description of $B$. arctoborealis sp. nov. In: R. Jahn, J.P. Kociolek, A. Witkowski \& P. Compère (eds.). Lange-BertalotFestschrift: Studies on Diatoms. A.R.G. Gantner Verlag. K.G, pp. 243-264. 